\title{
Cows selected for divergent mastitis susceptibility display a differential liver transcriptome profile after experimental Staphylococcus aureus mammary gland inoculation
}

\author{
A. Heimes, ${ }^{1} \oplus$ J. Brodhagen, ${ }^{1}$ R. Weikard, ${ }^{1} \oplus$ D. Becker, ${ }^{1} \oplus$ M. M. Meyerholz, ${ }^{2,3} \odot$ W. Petzl, ${ }^{2} \oplus$ H. Zerbe, ${ }^{2} \oplus$ \\ H.-J. Schuberth, ${ }^{3}$ (D) M. Hoedemaker, ${ }^{4}$ (i) M. Schmicke, ${ }^{5}$ (i) S. Engelmann, ${ }^{6,7}$ and C. Kühn ${ }^{1,8 *}$ (i) \\ ${ }^{1}$ Leibniz Institute for Farm Animal Biology (FBN), Institute of Genome Biology, 18196 Dummerstorf, Germany \\ ${ }^{2}$ Clinic for Ruminants with Ambulatory and Herd Health Services, Centre for Clinical Veterinary Medicine, Ludwig-Maximilians-University Munich, \\ 85764 Oberschleißheim, Germany \\ ${ }^{3}$ Immunology Unit, University of Veterinary Medicine Hannover, 30559 Hannover, Germany \\ ${ }^{4}$ Clinic for Cattle, University of Veterinary Medicine Hannover, 30173 Hannover, Germany \\ ${ }^{5}$ Faculty of Natural Sciences III, Martin-Luther Universität Halle-Wittenberg, 06120 Halle, Germany \\ ${ }^{6}$ Technical University Braunschweig, Institute for Microbiology, 38023 Braunschweig, Germany \\ ${ }^{7}$ Helmholtz Centre for Infection Research, Microbial Proteomics, 38124 Braunschweig, Germany \\ ${ }^{8}$ Agricultural and Environmental Faculty, University Rostock, 18059 Rostock, Germany
}

\begin{abstract}
Infection and inflammation of the mammary gland, and especially prevention of mastitis, are still major challenges for the dairy industry. Different approaches have been tried to reduce the incidence of mastitis. Genetic selection of cows with lower susceptibility to mastitis promises sustainable success in this regard. Bos taurus autosome (BTA) 18, particularly the region between 43 and $59 \mathrm{Mb}$, harbors quantitative trait loci (QTL) for somatic cell score, a surrogate trait for mastitis susceptibility. Scrutinizing the molecular bases hereof, we challenged udders from half-sib heifers having inherited either favorable paternal haplotypes for somatic cell score (Q) or unfavorable haplotypes (q) with the Staphylococcus aureus pathogen. RNA sequencing was used for an in-depth analysis of challenge-related alterations in the hepatic transcriptome. Liver exerts highly relevant immune functions aside from being the key metabolic organ. Hence, a holistic approach focusing on the liver enabled us to identify challenge-related and genotype-dependent differentially expressed genes and underlying regulatory networks. In response to the $S$. aureus challenge, we found that heifers with $\mathrm{Q}$ haplotypes displayed more activated immune genes and pathways after $S$. aureus challenge compared with their q half-sibs. Furthermore, we found a significant enrichment of differentially expressed loci in the genomic target region on BTA18, suggesting the existence of a regionally acting regulatory element with effects on a variety of genes in this region.
\end{abstract}

Received September 19, 2019.

Accepted February 15, 2020.

*Corresponding author: kuehn@fbn-dummerstorf.de
Key words: BTA18, mastitis, somatic cell score, liver transcriptome, RNAseq

\section{INTRODUCTION}

Rapid progress in molecular biology and genetics has made it possible to include information on genomic variance in modern animal breeding alternatively or complementary to the classical pedigree-based approach (Meuwissen et al., 2001; Matthews et al., 2019). Facing the challenges of rising antimicrobial resistances and an increasing awareness of animal welfare issues, this approach is particularly interesting for improving animal health (e.g., in dairy cattle). Genomic selection for reduced mastitis susceptibility is a sustainable option to reduce disease incidence, but it requires profound knowledge on the underlying genetic loci modulating the trait. In a previous study, Brand et al. (2009) identified QTL on BTA18 associated with SCS (calculated from the SCC) in the German Holstein population. The SCS strongly correlates with mastitis (Weller et al., 1992; Rupp and Boichard, 2003), the infection and inflammation of the mammary gland, one of the most common infectious diseases in dairy cows (Halasa et al., 2007; De Vliegher et al., 2012). Kühn et al. (2008) described that including genetic marker haplotype information associated with the SCS QTL on BTA18 improved selection for a favorable SCS compared with selection restricted to solely conventional pedigree information. Recently, differences between alternative paternally inherited BTA 18 haplotypes in clinical performance were confirmed for first lactating heifers before and after challenge with mastitis pathogens at the early lactation stage (Heimes et al., 2019; Meyerholz et al., 2019; Rohmeier et al., 2020). These 
results are in line with a large number of studies reporting a major QTL for functional traits (SCS, mastitis, longevity) in the respective genomic region on BTA18 (Brand et al., 2009, 2010; Mao et al., 2016; Müller et al., 2017; Wu et al., 2017; Fang et al., 2019). Hence, information on BTA18 haplotypes in Holstein cattle breeding could contribute to improved animal health and particularly to reduced susceptibility to mastitis in the German Holstein cattle population. However, haplotype effects need to be first characterized more precisely to exclude potential detrimental side effects. Furthermore, a deep phenotypic evaluation of potential BTA18 haplotype effects could also shed light on the precise causal molecular background of the QTL localized in this chromosomal region. The genetic variation underlying this major QTL is still unclear in spite of very powerful analyses and promising candidate genes (Fang et al., 2019; Jiang et al., 2019). The liver is at the center of the metabolic and immunological physiology of the dairy cow (Moyes et al., 2016). Hence, we focused in this study on the hepatic transcriptome using RNA sequencing (RNAseq) to gain comprehensive information about immunological as well as metabolic differences between divergent haplotypes at the transcriptomic level. Therefore, we have looked at the effects of an intramammary challenge with a mastitis pathogen on the hepatic transcriptome of half-sib cows, which had inherited either favorable or unfavorable paternal haplotypes. The challenge was performed with Staphylococcus aureus strain 1027, commonly known as a causative pathogen for subclinical mastitis (Schukken et al., 2011; Jensen et al., 2013).

\section{MATERIALS AND METHODS}

\section{Selection Process to Establish Experimental Animal Cohorts}

The selection process was described in detail by Heimes et al. (2019) and Meyerholz et al. (2019). Based on previous studies (Kühn et al., 2008; Brand et al., 2009), the targeted haplotypes were allocated to 2 BTA18 sub-regions (43-48 and 53-59 Mb). As presented earlier (Meyerholz et al., 2019) for all 11,503 German Holstein AI sires born between 1999 and 2012 and recorded in the VIT genome database, we calculated SNP effects for divergent paternal haplotypes in the respective chromosomal regions $(\mathbf{Q}$, meaning favorable for SCS, and $\mathbf{q}$, meaning unfavorable for SCS). We selected those sires with differences of summarized SNP effects of at least 2 standard deviations larger than the mean with the assumption that those sires should be segregating for a $\mathrm{Q}$ or q haplotype. We ex- cluded sires with extreme breeding values for SCS and milk performance traits to achieve similar performance levels within half-sib groups. The maternal grandsires were selected for their breeding values for SCS (Relativzuchtwert Somatischer Zellgehalt, above 112 for the Q cohort and below 100 for the q cohort). Moreover, we searched for cohorts with at least 3 potential Q and q half-sib sisters within one sire, respectively, and a maximal calving age of 36 mo. After all these filtering steps, a total of 282 heifers were genotyped with the $50 \mathrm{k}$ Illumina SNP chip (Illumina Inc., San Diego, CA) and haplotyped for their inherited paternal haplotypes (Q or q). Finally, 24 healthy, pregnant heifers, which originated from 6 sires, were selected. Within sire, each of the heifers was allocated to the Q or q group according to the inherited SNP haplotypes, which enabled monitoring of alternative paternally inherited haplotypes in the analysis. The selected heifers were purchased from conventional dairy farms across Germany and brought to the Clinic for Cattle at the University of Veterinary Medicine Hannover (Meyerholz et al., 2019).

\section{Challenge Experiment}

Twenty-four animals (12 Q, 12 q) were challenged in an infection model in the Clinic for Cattle at the University of Veterinary Medicine Hannover essentially as described in detail in Rohmeier et al. (2020). The husbandry of these cows was previously described by Meyerholz et al. (2019). Briefly, during the challenge experiment, the animals were kept in individual loose stall pens and received a component diet based on grass silage, corn silage, rapeseed extraction meal, soy extraction meal, concentrates, and minerals adjusted to milk performance. In the pre-challenge period, the animals were closely monitored for general health status and specific indicators of mastitis as described in Rohmeier et al. (2020). The experiment was performed under the reference number 33.12-42502-04-15/2024 with approval by the Lower Saxony Federal State Office for Consumer Protection and Food Safety. Furthermore, this study was approved by the ethics committee of the University of Veterinary Medicine Hannover. All ethical evaluations were performed as required by the German Animal Care law (Tierschutzgesetz, 2019).

The intramammary challenge experiment was based on previous work by our research group regarding selection of challenge dose and sampling time (Petzl et al., 2008, 2012). Thirty-six $\pm 3 \mathrm{~d}$ after parturition, 24 healthy animals (12 Q, 12 q) were challenged with $10,000 \mathrm{cfu}$ of $S$. aureus $s_{1027}$ each in both hind quarters of the mammary gland and killed $96 \mathrm{~h}$ later. A control udder quarter was infused with sterile sodium chloride 
solution. Heifers were closely monitored for clinical signs of mastitis [e.g., declining milk yield, local (pain, swelling, redness) or systemic (fever) signs of inflammation] during the postchallenge period as described by Rohmeier et al. (2020). The animals were stunned with a penetrating captive bolt pistol, immediately followed by exsanguination via longitudinal section of the jugular veins and carotid arteries $96 \mathrm{~h}$ after the start of the challenge (Meyerholz et al., 2019). The time point was selected because it was predicted to be the zenith of mammary gland inflammation according to experience from previous experiments (Petzl et al., 2008, 2012). During dissection of the animals, liver tissue was collected from the lobus caudatus, immediately shock frozen in liquid nitrogen, and subsequently stored at $-80^{\circ} \mathrm{C}$. About 6 mo after sampling, the tissue was used for transcriptome analysis as described below.

\section{Transcriptome Analysis by RNA Sequencing}

Frozen liver tissue samples (approximately $30 \mathrm{mg}$ ) were ground using the Precellys 24 tissue homogenizer with a lysing kit containing 1.4-mm ceramic beads (peQLab, Erlangen, Germany). Total RNA was extracted via an on-column purification following the protocol of the NucleoSpin RNA II kit (Macherey-Nagel, Düren, Germany), with an adapted DNase digestion step as described by Weikard et al. (2012). The total RNA was controlled for presence of genomic DNA by PCR (Weikard et al., 2009), and a second DNase digestion step was added if required. The RNA concentration and purity were quantified on a NanoDrop 2000 spectrophotometer (Thermo Fisher Scientific, Waltham, MA) and a Qubit 2.0 fluorometer (Thermo Fisher Scientific), and RNA integrity was evaluated on the Bioanalyzer 2100 (Agilent Technologies, Böblingen, Germany). Subsequently, a stranded library preparation protocol for RNA sequencing was applied (TruSeq Stranded mRNA LP, Illumina) with application of indices for multiplexing during cluster generation and polyA-selection to focus on polyadenylated RNA (in the majority mRNA). The RNAseq libraries were checked for quality on the Bioanalyzer 2100. Using the Illumina HiSeq 2500 system (Illumina), we performed paired-end sequencing $(2 \times 90 \mathrm{bp})$.

\section{Bioinformatic Analysis}

The CASAVA v1.8 (Illumina) software was used for demultiplexing of reads. Scripts written in SAMtools (Li et al., 2009), Linux, and R (R, 2016) were applied for data processing. We checked the quality of the raw reads with FastQC version 0.11.5 (FastQC, 2016) and
MultiQC version 1.4 (MultiQC, 2017). Adapters were removed using Cutadapt version 1.12 (Martin, 2011) and low-quality bases were removed using QualityTrim (Qualitytrim, 2017). The reads were aligned to the bovine reference genome UMD 3.1 with Ensembl 87 reference annotation (UMD3.1, 2016) using Hisat2 version 2.1.0 (Pertea et al., 2016). A guided transcript assembly was generated with StringTie version 1.3.2.d (Pertea et al., 2016). The advantage of this approach is that a guided transcript assembly refers to the reference genome annotation and also enables the identification of transcripts, which have not yet been annotated. Using the StringTie (Pertea et al., 2016) merge function, an annotation across samples was generated and read counting was carried out with FeatureCounts version 1.5.2 (FeatureCounts, 2017). Differential expression analysis was performed with DESeq2 version 1.18.1 (Love et al., 2014) with a threshold for significance of adjusted $P\left(P_{\text {adj }}\right)<0.05$. Ingenuity Pathway Analysis (Qiagen, Hilden, Germany) was used to identify enriched biological pathways and predicted upstream regulators in response to a pathogen challenge.

During the selection process for Q and q heifers, the cholesterol deficiency (CD) defect was detected in the German Holstein population (Kipp et al., 2016; Menzi et al., 2016). Hence, before final heifer selection, their CD carrier status was determined by haplotype analysis (Kipp et al., 2016). In the end, 4 heterozygous CD carriers (CDC according to the World Holstein Friesian Federation, http://www.whff.info/documentation/ genetictraits.php\#go1) were included in the design, which were offspring of a single sire. The CDC heifers were distributed evenly across the $\mathrm{Q}$ and q groups. The $\mathrm{CD}$ carrier status was included as fixed effect in the differential expression data analysis.

\section{RESULTS}

\section{RNA Sequencing Statistics}

The transcriptome analysis by RNAseq generated 2.6 billion reads (on average 107 million reads per sample). A total of $98 \%$ of reads mapped at least once to the reference genome UMD3.1 (UMD3.1, 2016). The data analysis revealed a total of 20,723 loci, which showed an expression level of at least 10 reads in at least 4 samples.

\section{Differential Hepatic Transcriptome Expression in Animals Infected with S. aureus}

In the expression analysis comparing $S$. aureus challenged animals that had either inherited the paternal 
Table 1. All significantly (adjusted $P$-value, $P_{\text {adj }}<0.05$ ) differentially expressed annotated genes in the differential expression analysis between paternally inherited haplotypes Q (favorable for SCS) versus q (unfavorable for SCS) of animals challenged with Staphylococcus aureus

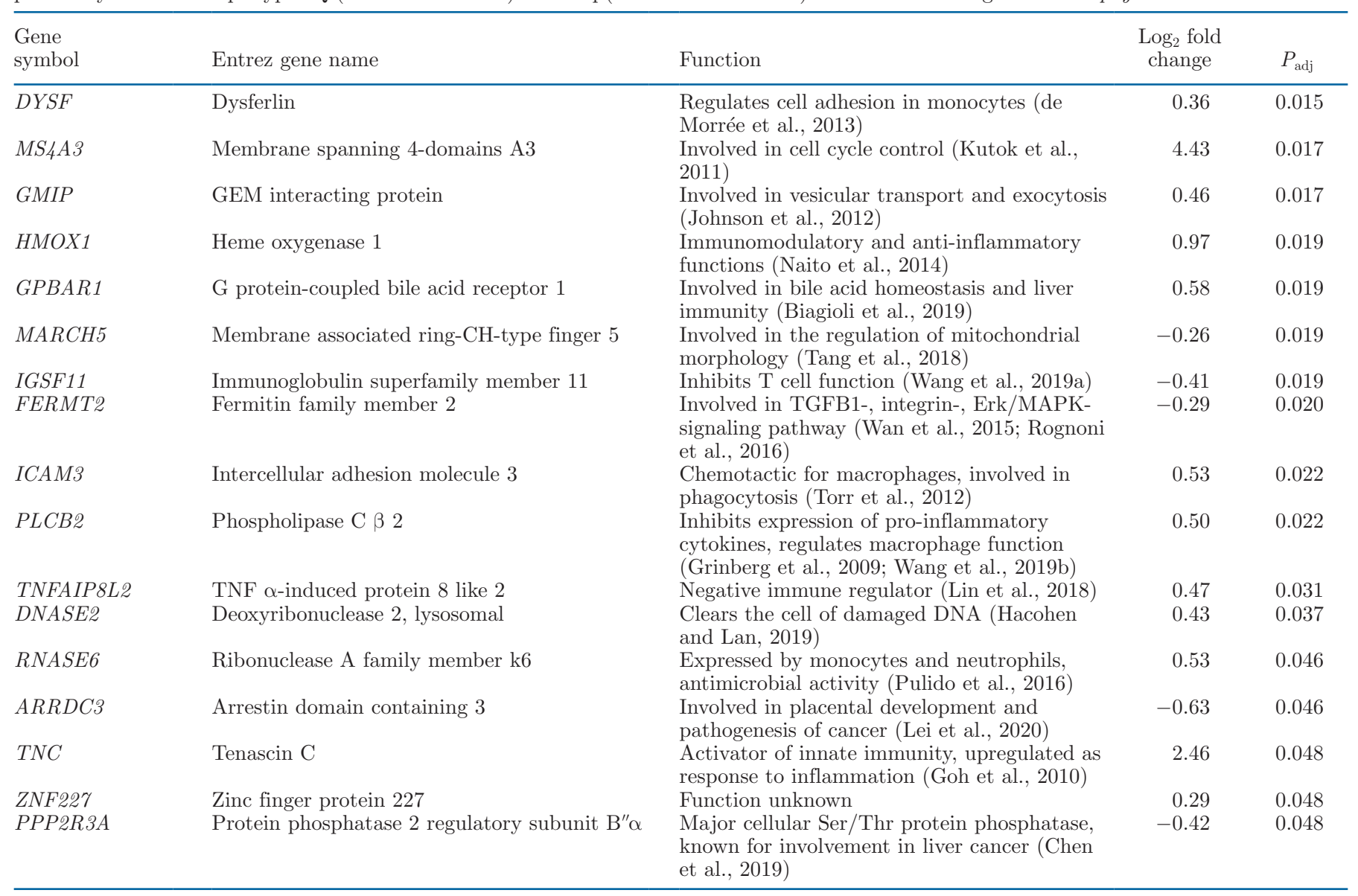

haplotypes $\mathrm{Q}(\mathrm{n}=12)$ or $\mathrm{q}(\mathrm{n}=12)$, we found a total of 23 significantly $\left(P_{\text {adj }}<0.05\right)$ differentially expressed (DE) loci (see Table 1 and Supplemental File S1; https: //doi.org/10.3168/jds.2019-17612). Of these 23 significantly DE loci, 17 were annotated genes $(74 \%)$, with 12 and 5 genes expressed at a higher and lower level, respectively, in Q compared with q animals.

Within the 17 annotated DE genes between paternally inherited haplotypes Q versus q of $S$. aureus challenged animals 10 genes are listed, which are involved in immune response [e.g., IGSF11 with known effects on human T cells (Wang et al., 2019a) and ICAM3, which is involved in apoptotic cell clearance (Torr et al., 2012)]. However, the top scorer of DE loci is a yet unannotated transcript on BTA18 located $2 \mathrm{Mb}$ outside the genomic target region for our haplotype selection (see Supplemental File S1). Another locus localized on BTA18 at $48.9 \mathrm{Mb}$ (according the UMD3.1) and still unannotated at the respective position in the current genome annotation ARS-UCD1.2 Ensembl 97 (https: //www.ensembl.org/Bos_taurus/Info/Index) showed significant differential expression (see Supplemental File S1). The respective transcript does also not show any sequence homology to annotated genes in human or mouse genomes. Three DE $\left(P_{\text {adj }}<0.05\right)$ loci are localized in the genomic region spanning 43 to $59 \mathrm{Mb}$ containing the targeted chromosomal subregions for haplotype selection on BTA18. Within this region, a total of 525 loci are expressed in our data set. Thus, compared with the total number of $23 \mathrm{DE}$ loci across all 20,724 expressed genomic loci in the entire genome there is a significant enrichment $(P<0.002)$ of DE loci in the BTA18 genomic region 43 to $59 \mathrm{Mb}$.

\section{Pathway Analysis of DE Genes in Animals Infected with S. aureus}

Ingenuity Pathway Analysis of those $17 \mathrm{DE}$ loci, which are annotated in the bovine reference genome assembly (UMD3.1), provided 24 significantly $(P<$ 0.05 ) enriched canonical pathways when comparing $S$. aureus challenged animals that had either inher- 
Table 2. All significantly $(P<0.05)$ canonical pathways enriched in the hepatic transcriptome of animals challenged with Staphylococcus aureus with haplotypes Q (favorable for SCS) versus q (unfavorable for SCS) using Ingenuity Pathway Analysis (Qiagen, Hilden, Germany)

\begin{tabular}{lc}
\hline Ingenuity canonical pathway & $\begin{array}{c}-\log _{10} \\
(P \text {-value })\end{array}$ \\
\hline Phospholipases & $2.94 \mathrm{E} 00$ \\
Antioxidant action of vitamin C & $2.55 \mathrm{E} 00$ \\
GPCR-mediated nutrient sensing in enteroendocrine cells & $2.52 \mathrm{E} 00$ \\
p70S6K signaling & $2.41 \mathrm{E} 00$ \\
D-myo-inositol-5-phosphate metabolism & $2.25 \mathrm{E} 00$ \\
Goq signaling & $2.24 \mathrm{E} 00$ \\
Dopamine-DARPP32 feedback in cAMP signaling & $2.18 \mathrm{E} 00$ \\
Heme degradation & $2.12 \mathrm{E} 00$ \\
ILK signaling & $2.11 \mathrm{E} 00$ \\
Synaptic long-term depression & $2.09 \mathrm{E} 00$ \\
Endothelin-1 signaling & $2.07 \mathrm{E} 00$ \\
IL-8 signaling & $2.06 \mathrm{E} 00$ \\
Breast cancer regulation by Stathmin1 & $2.05 \mathrm{E} 00$ \\
mTOR signaling & $2.01 \mathrm{E} 00$ \\
Superpathway of inositol phosphate compounds & $1.99 \mathrm{E} 00$ \\
Phospholipase C signaling & $1.84 \mathrm{E} 00$ \\
Choline biosynthesis III & $1.78 \mathrm{E} 00$ \\
Xenobiotic metabolism signaling & $1.77 \mathrm{E} 00$ \\
G Protein signaling mediated by tubby & $1.63 \mathrm{E} 00$ \\
D-myo-inositol (1,4,5)-trisphosphate biosynthesis & $1.62 \mathrm{E} 00$ \\
Cell cycle regulation by BTG family proteins & $1.60 \mathrm{E} 00$ \\
Role of CHK proteins in cell cycle checkpoint control & $1.41 \mathrm{E} 00$ \\
Wnt/Ca+ pathway & $1.35 \mathrm{E} 00$ \\
Mitotic roles of polo-like kinase & $1.35 \mathrm{E} 00$ \\
\hline
\end{tabular}

ited the paternal haplotypes $\mathrm{Q}$ or q (see Table 2 and Supplemental File S2; https://doi.org/10.3168/jds .2019-17612). Among them are the pathways integrinlinked protein kinase (ILK) signaling, IL-8 signaling, phospholipases, and phospholipase $\mathrm{C}$ signaling that are known to be directly related to immune response. The GPCR-mediated nutrient sensing in enteroendocrine cells, which was also significantly enriched between the paternal haplotypes $\mathrm{Q}$ or $\mathrm{q}$, provides a link between the immune response and the dairy cow's metabolism (Husted et al., 2017; Latorraca et al., 2017).

The analysis of the predicted upstream regulators (see Table 3) confirmed modulation of the hepatic immune system in Q heifers compared with the q halfsibs within $S$. aureus challenged animals. In the list of the top 10 significantly enriched upstream regulators (Table 3), 2 important immune receptors (CXCR3, C-X-C chemokine receptor type 3, and TLR3, toll-like receptor 3) as well as mitogen-activated protein kinase kinase kinase 1 (MAP3K1), a kinase involved in the TNF- $\alpha$ and NFkB signal cascades (Ishizuka et al., 1997), were found.

\section{DISCUSSION}

The heifers investigated in this study had been deeply phenotyped before and after the intramammary pathogen challenge as reported by Heimes et al. (2019), Meyerholz et al. (2019), and Rohmeier et al. (2020). The comparison of heifers with $\mathrm{Q}$ and $\mathrm{q}$ haplotypes revealed that the $q$ animals were more susceptible to early-lactation diseases. They had a higher number of udder quarters with very low cell count $(<10,000$ cells $/$ $\mathrm{mL}$ ) in the first weeks of lactation, but in the later course of lactation the weekly SCS was significantly lower for Q compared with q animals. The q animals had a higher SCS at 24 and $36 \mathrm{~h}$ after S. aureus challenge and a higher shedding of bacteria $12 \mathrm{~h}$ after challenge as well as a lower decline in milk yield after pathogen challenge (Heimes et al., 2019; Meyerholz et al., 2019; Rohmeier et al., 2020). Most interestingly, in addition to differences in clinical parameters there were also significant differences in the endocrine and metabolic profiles of the animals postpartum: those cows with Q haplotypes displayed higher IGF-1, lower growth hormone, and BHB levels in plasma and serum, respectively, compared with q half-sibs (Meyerholz et al., 2019).

The hepatic transcriptome is suitable to monitor potential metabolic as well as immunological effects of the BTA18 haplotypes, as the liver is at the center of the metabolic and immunological physiology of the dairy cow (Moyes et al., 2016). To follow up the differences in IGF-1, growth hormone, and BHB plasma/ serum levels between $\mathrm{Q}$ and $\mathrm{q}$ cows we had observed before the challenge, we looked at potential related hepatic transcriptomic signatures in $Q$ versus $q$ after intramammary $S$. aureus challenge. However, we did not find significant differences in gene expression for IGF1 or other key genes directly involved in (short chain) fatty acid metabolism (Supplemental File S1; https://doi.org/10.3168/jds.2019-17612). Interestingly, the canonical pathway GPCR-mediated nutrient sensing in enteroendocrine cells was significantly enriched in the hepatic transcriptome of $S$. aureus challenged animals with the $\mathrm{Q}$ haplotype compared with animals

Table 3. Top 10 significantly $(P<0.05)$ enriched upstream regulators in Ingenuity Pathway Analysis (Qiagen, Hilden, Germany) of haplotype Q (favorable for SCS) versus q (unfavorable for SCS) within animals challenged with Staphylococcus aureus (exogenous chemical excluded)

\begin{tabular}{lc}
\hline Upstream regulator & $P$-value of overlap \\
\hline GCH1 & $2.79 \mathrm{E}-05$ \\
SRF & $1.03 \mathrm{E}-04$ \\
CXCR3 & $1.51 \mathrm{E}-04$ \\
KDM3A & $4.10 \mathrm{E}-04$ \\
GABPA & $4.51 \mathrm{E}-04$ \\
FBXL17 & $7.35 \mathrm{E}-04$ \\
BRIP1 & $7.35 \mathrm{E}-04$ \\
MAP3K1 & $7.66 \mathrm{E}-04$ \\
TLR3 & $8.89 \mathrm{E}-04$ \\
CAT & $9.68 \mathrm{E}-04$ \\
\hline
\end{tabular}


with the q haplotype. G-protein-coupled receptors (GPCR) are membrane proteins, which detect their ligands (e.g., hormones, neurotransmitters, chemokines) in the extracellular matrix and can subsequently initiate the respective intracellular signaling cascades (Latorraca et al., 2017). In the gastrointestinal tract, nutrient metabolites activate GPCR, resulting in the secretion of gut and pancreatic hormones (Husted et al., 2017). However, GPCR can also act as pro- and anti-inflammatory regulators of immune cells (Husted et al., 2017). Thus, they have a broad spectrum of influence, and the enrichment of the respective pathway in the hepatic transcriptome of $S$. aureus challenged animals with $\mathrm{Q}$ haplotypes compared with the half-sibs carrying a $\mathrm{q}$ haplotype indicates haplotype-specific differences regarding their metabolic and immune profiles.

After the intramammary $S$. aureus challenge, the livers of $\mathrm{Q}$ or q cows showed a different hepatic transcriptomic profile with respect to immune genes (see Tables 1 and 2).

The enrichment of the canonical pathways ILK signaling and IL-8 signaling indicates that immune pathways play a dominant role in the response of the divergent hepatic transcriptome response to intramammary $S$. aureus challenge. This is also indicated by the nominally significant enrichment of the Protein Information Resource category "Innate immunity" ( $P$ $=1.1 \times 10^{-3}$ ) and also by the significantly $\mathrm{DE}$ genes themselves (see Table 1). DYSF, for example, which was originally observed for its role in muscle function, is involved in regulating cellular interactions, cell adhesion mechanisms, and has a function in inflammatory cells (de Morrée et al., 2013). The receptor encoded by GPBAR1 is implicated in the suppression of macrophage functions and regulation of energy homeostasis by bile acids and is also essential for the regulation of liver immunity (Biagioli et al., 2019). HMOX1 has been recognized as having major immunomodulatory and anti-inflammatory properties and has been regarded as an adaptive cellular response against inflammatory response and oxidative stress (reviewed by Naito et al., 2014). FERMT2 plays a role in the TGFB1 and integrin signaling pathways (reviewed by Rognoni et al., 2016) and is related to the Erk/MAPK signaling pathway (Wan et al., 2015). Furthermore, ICAM3 and IGSF11 are both members of the immunoglobulin super-family. ICAM3 has been described as chemotactic for macrophages and is therefore implicated in the phagocytosis of apoptotic cells (Torr et al., 2012), whereas IGSF11 inhibited $\mathrm{T}$ cell function in human blood cell culture (Wang et al., 2019a). TNC, described to be upregulated in inflamed tissues, is an activator of innate immunity, which can stimulate the synthesis of inflammatory cytokines (Goh et al., 2010). The PLCB2 gene, also significantly differentially expressed, is part of the significantly enriched canonical pathways phospholipases and phospholipase $\mathrm{C}$ signaling. As a key regulator for macrophage function, PLCB2 is involved in the switch from an inflammatory (M1) to an angiogenic (M2-like) macrophage phenotype (Grinberg et al., 2009). Moreover, it can inhibit the expression of pro-inflammatory cytokines (Wang et al., 2019b). As presented in Figure 1 , the Ingenuity network analysis showed that $D Y S F$, GPBAR1, HMOX1, FERMT2, ICAM3, TNC, and $P L C B 2$ are interacting with each other in a network related to immune response, indicating an interrelationship between them.

As potential transcriptional regulators CXCR3, TLR3, and MAP3K1 could be predicted (Table 3). The CXCR3 is expressed by monocytes, $\mathrm{T}$ cells, natural killer cells, dendritic cells, and cancer cells (Tokunaga et al., 2018). After activation by its selective ligands CXCL9, CXCL10, and CXCL11, it is involved in the recruitment and clustering of $\mathrm{T}$ cells and natural killer cells (Tokunaga et al., 2018; Maurice et al., 2019; Read et al., 2019). Toll-like receptor 3 is widely known for its crucial role in pathogen recognition and subsequent activation of innate immunity (Chen et al., 2017). Mitogen-activated protein kinase kinase kinase 1 takes

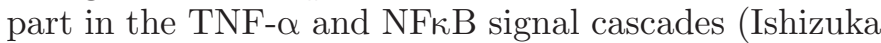
et al., 1997; Sanchez-Perez et al., 2002) and is therefore eminent for the appropriate response of the immune system to invasive pathogens. Thus, the upstream analysis confirmed alteration of the hepatic immune system in Q heifers compared with their q half-sibs within $S$. aureus-challenged animals.

Regarding a potential molecular background of the QTL for functional traits and udder health in particular, we found a significant enrichment of DE loci in the genomic target area of the different haplotypes and their close vicinity on BTA18. This suggests that a regionally acting regulatory element might be involved, which could modulate the expression of an array of genes located there. Regulatory variation in noncoding regions as background of the BTA18 telomeric functional QTL might also explain the lack of causal candidate variant evidence for this QTL. No causal mechanism for the QTL could be pinpointed despite genetic variants with predicted effects in coding and noncoding regions, as described in recent GWAS at the whole genome sequence level with powerful data sets (Wang et al., 2017; Fang et al., 2019; Jiang et al., 2019). This also underlines the need to improve the current annotation of the bovine genome in terms of functional regula- 


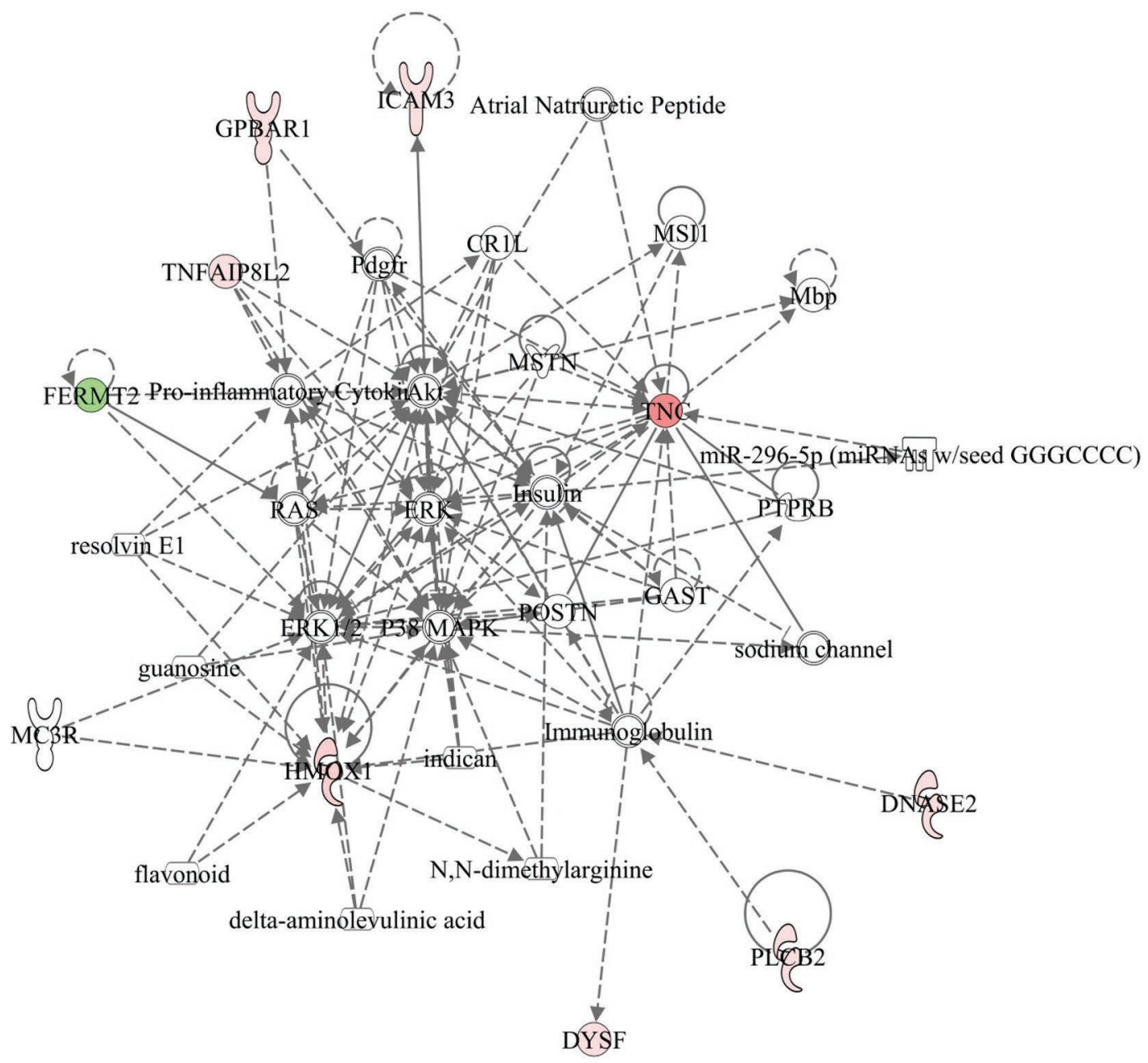

Figure 1. Highly enriched network in the differentially expressed gene analysis of Q (favorable paternal haplotypes for SCS) versus q (unfavorable haplotypes for SCS) in cows challenged with Staphylococcus aureus. Green $=$ lower expression in Q cows compared with q cows, red $=$ higher expression in Q compared with q cows (modified according to Ingenuity Pathway Analysis, Qiagen, Hilden, Germany).

tory elements as addressed by the global Functional Annotation of Animal Genomes action (https://www .animalgenome.org/community/FAANG/; Andersson et al., 2015).

\section{CONCLUSIONS}

Heifers with alternative paternal BTA18 haplotypes display a significantly different hepatic transcriptome upon intramammary $S$. aureus challenge. Animals with the favorable $\mathrm{Q}$ haplotypes showed a more activated immune system (as demonstrated by the higher activation of key pathways and divergent expression of relevant immune genes), which might be better able to defend the host during a bacterial challenge. Driver of these differences in the immune system might be different adaptations of metabolic pathways of the $\mathrm{Q}$ and $\mathrm{q}$ animals. These findings are in line with results from clinical data of the haplotypes, which showed Q cows to be more resistant to diseases, especially $S$. aureus mastitis (SCC, SCS, shedding of bacteria, milk yield) than their q half-sibs.

\section{ACKNOWLEDGMENTS}

The authors thank the laboratory staff at the FBN Dummerstorf as well as the $\mathrm{PhD}$ students of the ChronMast project at the University of Veterinary Medicine Hannover. We thankfully acknowledge HansMartin Seyfert (Dummerstorf, Germany) for very fruitful discussion. We also thank the Förderverein Bioökonomieforschung (Bonn, Germany) for continuous support. This work was supported by funds of the German Government's Special Purpose Fund held at 
Landwirtschaftliche Rentenbank (Frankfurt/Main, Germany). The authors have not stated any conflicts of interest.

\section{REFERENCES}

Andersson, L., A. L. Archibald, C. D. Bottema, R. Brauning, S. C. Burgess, D. W. Burt, E. Casas, H. H. Cheng, L. Clarke, C. Couldrey, B. P. Dalrymple, C. G. Elsik, S. Foissac, E. Giuffra, M. A. Groenen, B. J. Hayes, L. S. Huang, H. Khatib, J. W. Kijas, H. Kim, J. K. Lunney, F. M. McCarthy, J. C. McEwan, S. Moore, B. Nanduri, C. Notredame, Y. Palti, G. S. Plastow, J. M. Reecy, G. A. Rohrer, E. Sarropoulou, C. J. Schmidt, J. Silverstein, R. L. Tellam, M. Tixier-Boichard, G. Tosser-Klopp, C. K. Tuggle, J. Vilkki, S. N. White, S. Zhao, and H. Zhou. 2015. Coordinated international action to accelerate genome-to-phenome with FAANG, the Functional Annotation of Animal Genomes project. Genome Biol. 16:57. https://doi.org/10.1186/s13059-015-0622-4.

Biagioli, M., A. Carino, C. Fiorucci, S. Marchianò, C. Di Giorgio, R. Roselli, M. Magro, E. Distrutti, O. Bereshchenko, P. Scarpelli, A. Zampella, and S. Fiorucci. 2019. GPBAR1 functions as gatekeeper for liver NKT cells and provides counterregulatory signals in mouse models of immune-mediated hepatitis. Cell. Mol. Gastroenterol. Hepatol. 8:447-473. https://doi.org/10.1016/j.jcmgh.2019 .06 .003 .

Brand, B., C. Baes, M. Mayer, N. Reinsch, and C. Kuhn. 2009. Identification of a two-marker-haplotype on Bos taurus autosome 18 associated with somatic cell score in German Holstein cattle. BMC Genet. 10:50. https://doi.org/10.1186/1471-2156-10-50.

Brand, B., C. Baes, M. Mayer, N. Reinsch, T. Seidenspinner, G. Thaller, and C. Kuhn. 2010. Quantitative trait loci mapping of calving and conformation traits on Bos taurus autosome 18 in the German Holstein population. J. Dairy Sci. 93:1205-1215. https:// doi.org/10.3168/jds.2009-2553.

Chen, H., J. Xu, P. Wang, Q. Shu, L. Huang, J. Guo, X. Zhang, H. Zhang, Y. Wang, Z. Shen, X. Chen, and Q. Zhang. 2019. Protein phosphatase 2 regulatory subunit B"Alpha silencing inhibits tumor cell proliferation in liver cancer. Cancer Med. 8:7741-7753. https://doi.org/10.1002/cam4.2620.

Chen, N., P. Xia, S. Li, T. Zhang, T. T. Wang, and J. Zhu. 2017. RNA sensors of the innate immune system and their detection of pathogens. IUBMB Life 69:297-304. https://doi.org/10.1002/iub.1625.

de Morrée, A., B. Flix, I. Bagaric, J. Wang, M. van den Boogaard, L. Grand Moursel, R. R. Frants, I. Illa, E. Gallardo, R. Toes, and S. M. van der Maarel. 2013. Dysferlin regulates cell adhesion in human monocytes. J. Biol. Chem. 288:14147-14157. https://doi.org/ 10.1074/jbc.M112.448589.

De Vliegher, S., L. K. Fox, S. Piepers, S. McDougall, and H. W. Barkema. 2012. Invited review: Mastitis in dairy heifers: Nature of the disease, potential impact, prevention, and control. J. Dairy Sci. 95:1025-1040. https://doi.org/10.3168/jds.2010-4074.

Fang, L., J. Jiang, B. Li, Y. Zhou, E. Freebern, P. M. Vanraden, J. B. Cole, G. E. Liu, and L. Ma. 2019. Genetic and epigenetic architecture of paternal origin contribute to gestation length in cattle. Commun. Biol. 2:100. https://doi.org/10.1038/s42003-019-0341-6.

FastQC. 2016. Accessed Dec. 15, 2016. https://www.bioinformatics .babraham.ac.uk/projects/fastqc/.

FeatureCounts. 2017. Accessed Nov. 29, 2017. http://subread .sourceforge.net/.

Goh, F. G., A. M. Piccinini, T. Krausgruber, I. A. Udalova, and K. S. Midwood. 2010. Transcriptional regulation of the endogenous danger signal tenascin-C: A novel autocrine loop in inflammation. J. Immunol. 184:2655-2662. https://doi.org/10.4049/jimmunol .0903359 .

Grinberg, S., G. Hasko, D. Wu, and S. J. Leibovich. 2009. Suppression of PLCbeta2 by endotoxin plays a role in the adenosine $\mathrm{A}(2 \mathrm{~A})$ receptor-mediated switch of macrophages from an inflammatory to an angiogenic phenotype. Am. J. Pathol. 175:2439-2453. https: //doi.org/10.2353/ajpath.2009.090290.
Hacohen, N., and Y. Y. Lan. 2019. Damaged DNA marching out of aging nucleus. Aging (Albany NY) 11:8039-8040. https://doi.org/ 10.18632/aging. 102340 .

Halasa, T., K. Huijps, O. Osteras, and H. Hogeveen. 2007. Economic effects of bovine mastitis and mastitis management: a review. Vet. Q. 29:18-31. https://doi.org/10.1080/01652176.2007.9695224.

Heimes, A., J. Brodhagen, R. Weikard, H. M. Hammon, M. M. Meyerholz, W. Petzl, H. Zerbe, S. Engelmann, M. Schmicke, M. Hoedemaker, H. J. Schuberth, and C. Kuhn. 2019. Characterization of functional traits with focus on udder health in heifers with divergent paternally inherited haplotypes on BTA18. BMC Vet. Res. 15:241. https://doi.org/10.1186/s12917-019-1988-4.

Husted, A. S., M. Trauelsen, O. Rudenko, S. A. Hjorth, and T. W. Schwartz. 2017. GPCR-mediated signaling of metabolites. Cell Metab. 25:777-796. https://doi.org/10.1016/j.cmet.2017.03.008.

Ishizuka, T., N. Terada, P. Gerwins, E. Hamelmann, A. Oshiba, G. R. Fanger, G. L. Johnson, and E. W. Gelfand. 1997. Mast cell tumor necrosis factor alpha production is regulated by MEK kinases. Proc. Natl. Acad. Sci. USA 94:6358-6363. https://doi.org/ 10.1073/pnas.94.12.6358.

Jensen, K., J. Günther, R. Talbot, W. Petzl, H. Zerbe, H.-J. Schuberth, H.-M. Seyfert, and E. J. Glass. 2013. Escherichia coli- and Staphylococcus aureus-induced mastitis differentially modulate transcriptional responses in neighbouring uninfected bovine mammary gland quarters. BMC Genomics 14:36. https://doi.org/10.1186/ 1471-2164-14-36.

Jiang, J., J. B. Cole, E. Freebern, Y. Da, P. M. VanRaden, and L. Ma. 2019. Functional annotation and Bayesian fine-mapping reveals candidate genes for important agronomic traits in Holstein bulls. Commun. Biol. 2:212. https://doi.org/10.1038/s42003-019-0454-y.

Johnson, J. L., J. Monfregola, G. Napolitano, W. B. Kiosses, and S. D. Catz. 2012. Vesicular trafficking through cortical actin during exocytosis is regulated by the Rab27a effector JFC1/Slp1 and the RhoA-GTPase-activating protein Gem-interacting protein. Mol. Biol. Cell 23:1902-1916. https://doi.org/10.1091/mbc.e11-12 $-1001$.

Kipp, S., D. Segelke, S. Schierenbeck, F. Reinhardt, R. Reents, C. Wurmser, H. Pausch, R. Fries, G. Thaller, J. Tetens, J. Pott, D. Haas, B. B. Raddatz, M. Hewicker-Trautwein, I. Proios, M. Schmicke, and W. Grunberg. 2016. Identification of a haplotype associated with cholesterol deficiency and increased juvenile mortality in Holstein cattle. J. Dairy Sci. 99:8915-8931. https://doi .org/10.3168/jds.2016-11118.

Kühn, C., F. Reinhardt, and M. Schwerin. 2008. Marker assisted selection of heifers improved milk somatic cell count compared to selection on conventional pedigree breeding values. Arch. Tierzucht 51:23-32. https://doi.org/10.5194/aab-51-23-2008.

Kutok, J. L., X. Yang, R. Folkerth, and C. N. Adra. 2011. Characterization of the expression of HTm4 (MS4A3), a cell cycle regulator, in human peripheral blood cells and normal and malignant tissues. J. Cell. Mol. Med. 15:86-93. https://doi.org/10.1111/j.1582-4934 2009.00925.x.

Latorraca, N. R., A. J. Venkatakrishnan, and R. O. Dror. 2017. GPCR dynamics: Structures in motion. Chem. Rev. 117:139-155. https:/ /doi.org/10.1021/acs.chemrev.6b00177.

Lei, D., N. Deng, S. Wang, J. Huang, and C. Fan. 2020. Upregulated ARRDC3 limits trophoblast cell invasion and tube formation and is associated with preeclampsia. Placenta 89:10-19. https://doi .org/10.1016/j.placenta.2019.10.009.

Li, H., B. Handsaker, A. Wysoker, T. Fennell, J. Ruan, N. Homer, G. Marth, G. Abecasis, and R. Durbin. 2009. The Sequence Alignment/Map format and SAMtools. Bioinformatics 25:2078-2079. https://doi.org/10.1093/bioinformatics/btp352.

Lin, Z., W. Liu, C. Xiao, Y. Fan, G. Zhuang, and Z. Qi. 2018. TIPE2 inhibits GC via regulation of cell proliferation, apoptosis and inflammation. Oncol. Rep. 40:1307-1316. https://doi.org/10.3892/ or.2018.6576.

Love, M. I., W. Huber, and S. Anders. 2014. Moderated estimation of fold change and dispersion for RNA-seq data with DESeq2. Genome Biol. 15:550. https://doi.org/10.1186/s13059-014-0550-8. 
Mao, X., N. K. Kadri, J. R. Thomasen, D. J. De Koning, G. Sahana, and B. Guldbrandtsen. 2016. Fine mapping of a calving QTL on Bos taurus autosome 18 in Holstein cattle. J. Anim. Breed. Genet. 133:207-218. https://doi.org/10.1111/jbg.12187.

Martin, M. 2011. Cutadapt removes adapter sequences from highthroughput sequencing reads. EMBnet.journal 17. https://doi .org/10.14806/ej.17.1.200.

Matthews, D., J. F. Kearney, A. R. Cromie, F. S. Hely, and P. R. Amer. 2019. Genetic benefits of genomic selection breeding programmes considering foreign sire contributions. Genet. Sel. Evol. 51:40. https://doi.org/10.1186/s12711-019-0483-5.

Maurice, N. J., M. J. McElrath, E. Andersen-Nissen, N. Frahm, and M. Prlic. 2019. CXCR3 enables recruitment and site-specific bystander activation of memory CD8(+) T cells. Nat. Commun. 10:4987. https://doi.org/10.1038/s41467-019-12980-2.

Menzi, F., N. Besuchet-Schmutz, M. Fragniere, S. Hofstetter, V. Jagannathan, T. Mock, A. Raemy, E. Studer, K. Mehinagic, N. Regenscheit, M. Meylan, F. Schmitz-Hsu, and C. Drogemuller. 2016. A transposable element insertion in APOB causes cholesterol deficiency in Holstein cattle. Anim. Genet. 47:253-257. https://doi .org/10.1111/age.12410.

Meuwissen, T. H., B. J. Hayes, and M. E. Goddard. 2001. Prediction of total genetic value using genome-wide dense marker maps. Genetics 157:1819-1829.

Meyerholz, M. M., L. Rohmeier, T. Eickhoff, A. Hülsebusch, S. Jander, M. Linden, L. Macias, M. Koy, A. Heimes, L. Gorríz-Martín, D. Segelke, S. Engelmann, M. Schmicke, M. Hoedemaker, W. Petzl, H. Zerbe, H. J. Schuberth, and C. Kühn. 2019. Genetic selection for bovine chromosome 18 haplotypes associated with divergent somatic cell score affects postpartum reproductive and metabolic performance. J. Dairy Sci. 102:9983-9994. https://doi.org/10 $.3168 /$ jds.2018-16171.

Moyes, K. M., P. Sørensen, and M. Bionaz. 2016. The impact of intramammary Escherichia coli challenge on liver and mammary transcriptome and cross-talk in dairy cows during early lactation using RNAseq. PLoS One 11:e0157480. https://doi.org/10.1371/journal pone.0157480.

Müller, M. P., S. Rothammer, D. Seichter, I. Russ, D. Hinrichs, J. Tetens, G. Thaller, and I. Medugorac. 2017. Genome-wide mapping of 10 calving and fertility traits in Holstein dairy cattle with special regard to chromosome 18. J. Dairy Sci. 100:1987-2006. https://doi.org/10.3168/jds.2016-11506.

MultiQC. 2017. Accessed Sep. 11, 2017. http://multiqc.info/.

Naito, Y., T. Takagi, and Y. Higashimura. 2014. Heme oxygenase-1 and anti-inflammatory M2 macrophages. Arch. Biochem. Biophys. 564:83-88. https://doi.org/10.1016/j.abb.2014.09.005.

Pertea, M., D. Kim, G. M. Pertea, J. T. Leek, and S. L. Salzberg. 2016. Transcript-level expression analysis of RNA-seq experiments with HISAT, StringTie and Ballgown. Nat. Protoc. 11:1650-1667. https://doi.org/10.1038/nprot.2016.095.

Petzl, W., J. Gunther, T. Pfister, C. Sauter-Louis, L. Goetze, S. von Aulock, A. Hafner-Marx, H. J. Schuberth, H. M. Seyfert, and H. Zerbe. 2012. Lipopolysaccharide pretreatment of the udder protects against experimental Escherichia coli mastitis. Innate Immun. 18:467-477. https://doi.org/10.1177/1753425911422407.

Petzl, W., H. Zerbe, J. Gunther, W. Yang, H. M. Seyfert, G. Nurnberg, and H. J. Schuberth. 2008. Escherichia coli, but not Staphylococcus aureus triggers an early increased expression of factors contributing to the innate immune defense in the udder of the cow. Vet. Res. 39:18. https://doi.org/10.1051/vetres:2007057.

Pulido, D., J. Arranz-Trullen, G. Prats-Ejarque, D. Velazquez, M. Torrent, M. Moussaoui, and E. Boix. 2016. Insights into the antimicrobial mechanism of action of human RNase6: Structural determinants for bacterial cell agglutination and membrane permeation. Int. J. Mol. Sci. 17:552. https://doi.org/10.3390/ijms17040552.

Qualitytrim. 2017. Accessed Sep. 11, 2017. https://bitbucket.org/ arobinson/qualitytrim.

R. 2016. Accessed August 29, 2016. https://www.r-project.org/.

Read, S. A., R. Wijaya, M. Ramezani-Moghadam, E. Tay, S. Schibeci, C. Liddle, V. W. T. Lam, L. Yuen, M. W. Douglas, D. Booth, J.
George, and G. Ahlenstiel. 2019. Macrophage coordination of the Interferon Lambda immune response. Front. Immunol. 10:2674. https://doi.org/10.3389/fimmu.2019.02674.

Rognoni, E., R. Ruppert, and R. Fässler. 2016. The kindlin family: Functions, signaling properties and implications for human disease. J. Cell Sci. 129:17-27. https://doi.org/10.1242/jcs.161190.

Rohmeier, L., W. Petzl, M. Koy, T. Eickhoff, A. Hülsebusch, S. Jander, L. Macias, A. Heimes, S. Engelmann, M. Hoedemaker, H. M. Seyfert, C. Kühn, H. J. Schuberth, H. Zerbe, and M. M. Meyerholz. 2020. In vivo model to study the impact of genetic variation on clinical outcome of mastitis in dairy heifers. BMC Vet Res. 16:33. https://doi.org/10.1186/s12917-020-2251-8.

Rupp, R., and D. Boichard. 2003. Genetics of resistance to mastitis in dairy cattle. Vet. Res. 34:671-688. https://doi.org/10.1051/vetres: 2003020.

Sanchez-Perez, I., S. A. Benitah, M. Martinez-Gomariz, J. C. Lacal, and R. Perona. 2002. Cell stress and MEKK1-mediated c-Jun activation modulate NFkappaB activity and cell viability. Mol. Biol. Cell 13:2933-2945. https://doi.org/10.1091/mbc.e02-01-0022.

Schukken, Y. H., J. Gunther, J. Fitzpatrick, M. C. Fontaine, L. Goetze, O. Holst, J. Leigh, W. Petzl, H. J. Schuberth, A. Sipka, D. G. Smith, R. Quesnell, J. Watts, R. Yancey, H. Zerbe, A. Gurjar, R. N. Zadoks, and H. M. Seyfert. 2011. Host-response patterns of intramammary infections in dairy cows. Vet. Immunol. Immunopathol. 144:270-289. https://doi.org/10.1016/j.vetimm.2011.08 .022 .

Tang, H., S. Peng, Y. Dong, X. Yang, P. Yang, L. Yang, B. Yang, and G. Bao. 2018. MARCH5 overexpression contributes to tumor growth and metastasis and associates with poor survival in breast cancer. Cancer Manag. Res. 11:201-215. https://doi.org/10.2147/ CMAR.S190694.

Tierschutzgesetz. 2019. Accessed Jun. 13, 2019. https://www.gesetze -im-internet.de/tierschg/BJNR012770972.html.

Tokunaga, R., W. Zhang, M. Naseem, A. Puccini, M. D. Berger, S. Soni, M. McSkane, H. Baba, and H. J. Lenz. 2018. CXCL9, CXCL10, CXCL11/CXCR3 axis for immune activation - A target for novel cancer therapy. Cancer Treat. Rev. 63:40-47. https://doi .org/10.1016/j.ctrv.2017.11.007.

Torr, E. E., D. H. Gardner, L. Thomas, D. M. Goodall, A. Bielemeier, R. Willetts, H. R. Griffiths, L. J. Marshall, and A. Devitt. 2012 Apoptotic cell-derived ICAM-3 promotes both macrophage chemoattraction to and tethering of apoptotic cells. Cell Death Differ. 19:671-679. https://doi.org/10.1038/cdd.2011.167.

UMD3.1. 2016. Accessed Mar. 21, 2016. ftp://ftp.ensembl.org/././ pub/release-87/fasta/bos_taurus/dna/.

Wan, C., B. Borgeson, S. Phanse, F. Tu, K. Drew, G. Clark, X. Xiong, O. Kagan, J. Kwan, A. Bezginov, K. Chessman, S. Pal, G. Cromar, O. Papoulas, Z. Ni, D. R. Boutz, S. Stoilova, P. C. Havugimana, X. Guo, R. H. Malty, M. Sarov, J. Greenblatt, M. Babu, W. B. Derry, E. R. Tillier, J. B. Wallingford, J. Parkinson, E. M. Marcotte, and A. Emili. 2015. Panorama of ancient metazoan macromolecular complexes. Nature 525:339. https://doi.org/10.1038/nature14877.

Wang, J., G. Wu, B. Manick, V. Hernandez, M. Renelt, C. Erickson, J. Guan, R. Singh, S. Rollins, A. Solorz, M. Bi, J. Li, D. Grabowski, J. Dirkx, C. Tracy, T. Stuart, C. Ellinghuysen, D. Desmond, C. Foster, and V. Kalabokis. 2019a. VSIG-3 as a ligand of VISTA inhibits human T-cell function. Immunology 156:74-85. https:// doi.org/10.1111/imm.13001.

Wang, L., Y. Zhou, Z. Chen, L. Sun, J. Wu, H. Li, F. Liu, F. Wang, C. Yang, J. Yang, Q. Leng, Q. Zhang, A. Xu, L. Shen, J. Sun, D. Wu, C. Fang, H. Lu, D. Yan, and B. Ge. 2019b. PLCbeta2 negatively regulates the inflammatory response to virus infection by inhibiting phosphoinositide-mediated activation of TAK1. Nat. Commun. 10:746. https://doi.org/10.1038/s41467-019-08524-3.

Wang, T., Y. P. Chen, I. M. MacLeod, J. E. Pryce, M. E. Goddard, and B. J. Hayes. 2017. Application of a Bayesian non-linear model hybrid scheme to sequence data for genomic prediction and QTL mapping. BMC Genomics 18:618. https://doi.org/10.1186/s12864 $-017-4030-\mathrm{x}$. 
Weikard, R., T. Goldammer, R. M. Brunner, and C. Kuehn. 2012. Tissue-specific mRNA expression patterns reveal a coordinated metabolic response associated with genetic selection for milk production in cows. Physiol. Genomics 44:728-739. https://doi.org/10 .1152 /physiolgenomics.00007.2012.

Weikard, R., T. Goldammer, A. Eberlein, and C. Kuehn. 2009. Novel transcripts discovered by mining genomic DNA from defined regions of bovine chromosome 6. BMC Genomics 10:186. https://doi .org/10.1186/1471-2164-10-186.

Weller, J. I., A. Saran, and Y. Zeliger. 1992. Genetic and environmental relationships among somatic cell count, bacterial infection, and clinical mastitis. J. Dairy Sci. 75:2532-2540. https://doi.org/10 .3168/jds.S0022-0302(92)78015-1.

Wu, X. P., B. Guldbrandtsen, U. S. Nielsen, M. S. Lund, and G. Sahana. 2017. Association analysis for young stock survival index with imputed whole-genome sequence variants in Nordic Holstein cattle. J. Dairy Sci. 100:6356-6370. https://doi.org/10.3168/jds .2017-12688.

\section{ORCIDS}

A. Heimes $\odot$ https://orcid.org/0000-0003-0638-0596

R. Weikard ๑ https://orcid.org/0000-0002-0308-9966

D. Becker $\odot$ https://orcid.org/0000-0003-0425-6284

M. M. Meyerholz () https://orcid.org/0000-0003-1720-6593

W. Petzl ๑ https://orcid.org/0000-0002-7931-2642

H. Zerbe (ㄴ) https://orcid.org/0000-0002-7972-4858

H.-J. Schuberth ๑ https://orcid.org/0000-0002-5904-5751

M. Hoedemaker ( ) https://orcid.org/0000-0001-8154-2642

M. Schmicke @ https://orcid.org/0000-0001-7218-293X

C. Kühn () https://orcid.org/0000-0002-0216-424X 